\title{
Optimal nocturnal sleep duration to maintain health- related quality of life in male collegiate athletes: a cross-sectional study
}

Yuko Morita ( $\nabla$ moritayuko@rs.tus.ac.jp )

Tokyo University of Science

Taeko Sasai-Sakuma

Teikyo University

\section{Research Article}

Keywords: athlete, sleep duration, Health-related quality of life, insufficient sleep

Posted Date: November 24th, 2021

DOI: https://doi.org/10.21203/rs.3.rs-1094107/v1

License: (c) (1) This work is licensed under a Creative Commons Attribution 4.0 International License.

Read Full License 


\section{Abstract}

Background: This study investigated the optimal nocturnal sleep duration required by collegiate athletes to maintain physical and mental health, compared with non-athlete students.

Methods: In this cross-sectional study, a questionnaire survey was conducted to assess demographic variables, lifestyle and sleep habits, and health-related quality of life in 298 collegiate students (nonathletes, $n=158$; athletes, $n=140$ ). Physical component summary and mental component summary were assessed by using a Short-Form 8 Health survey, and participants with good physical as well as mental component summary scores were considered to have a good health-related quality of life. To confirm an association between nocturnal sleep length and good health-related quality of life, logistic regression analyses were conducted in non-athlete students and collegiate athletes separately.

Subsequently, receiver operating characteristics curve analyses were performed for detection of the cutoff points for nocturnal sleep duration sufficient to maintain good health-related quality of life in both collegiate athletes and non-athlete students.

Results: The average nocturnal sleep duration was 7 hours 4 minutes among collegiate athletes, and $75.7 \%$ of them had a worse physical component summary. The cut-off point for nocturnal sleep duration in collegiate athletes was 7.98 hours (area under the curve: $0.69, P=0.013$, sensitivity: $85.5 \%$, specificity: $56.2 \%)$, which was longer than the cut-off of 6.58 hours for non-athlete students.

Conclusion: Collegiate athletes required longer nocturnal sleep than non-athlete students. Nevertheless, their habitual nocturnal sleep duration was shorter compared to their optimal duration; around $80 \%$ of them faced chronic insufficient sleep. Improving sleep habits and sleep education is important in maintaining their good health-related quality of life.

\section{Introduction}

Almost all athletes aim to perform their best and ultimately win competitions. In order to reach these goals, optimal recovery from physical exhaustion is required in addition to daily training or practice. Sufficient sleep is widely known to be beneficial for recovery $[1,2]$.

Insufficient sleep (even deprivation of one night's sleep) often leads to decreased physical performance, such as reduced aerobic [3] and anaerobic capacities [4] and impaired psychological or cognitive performance in areas such as attention, concentration, and cognition [5,6]. Additionally, sleep loss causes mood disturbance due to decreasing energy levels, fatigue, or confusion [7], consequently decreasing the mental and physical quality of life [8].

A few previous studies have assessed the sleep habits of athletes. One study suggested that athletes got 5.5 hours of nocturnal sleep [9], while another study reported a duration of 6.6 hours, which was shorter than the duration of 7.1 hours observed in non-athletes [10]. Furthermore, the habitual nocturnal sleep duration in athletes is much less than that of the 8.2 hours required for young adults to maintain their 
cognitive functions [11]. Therefore, considering the number of daily exercises that athletes undertake, it is assumed that they need longer sleep durations than non-athletes in order to recover from exhaustion. However, most athletes do not get enough sleep to maintain their mental and physical health.

Particularly among collegiate athletes, it is speculated that there is a higher rate of insufficient sleep because, in addition to practice and training, they also need to spend additional time in classes, studying, and doing part-time jobs. Indeed, a recent study indicated that collegiate student-athletes had an average of 6.98 hours of nocturnal sleep on weekdays. Of them, $39.1 \%$ experienced inadequate sleep, which was defined as regularly obtaining $<7$ hours of sleep on weekdays, and $51.0 \%$ experienced daytime sleepiness [12]. Additionally, the severity of insufficient sleep may be higher in young adults because they have greater sleep needs than middle-aged or older adults. Thus, when sleep-deprived athletes continue to practice, train, and compete, they not only underperform but are also prone to injuries or the development of mental disorders, which have harmful effects on their future careers. In addition, the experience of sport-related disorders in collegiate athletes may not only prevent them from achieving their desired career goals in sports but may also decrease their future health-related quality of life (HRQOL) [13].

Therefore, considering these factors, it is important to understand the sleep habits of collegiate athletes and determine the optimal nocturnal sleep duration required to maintain physical and mental health. To the best of our knowledge, no previous study has examined this issue precisely. Therefore, we conducted a survey of sleep and lifestyle habits in collegiate athletes and compared it with that in non-athlete students to determine the optimal nocturnal sleep duration, which contributes to maintaining optimum physical and mental health.

\section{Methods}

Participants and procedures

This cross-sectional questionnaire-based study was conducted from October 2015 to December 2015. Students belonging to top competitive-level university sports teams were included as collegiate athletes, while non-athlete students from a private university were included in the control group. The questionnaire was distributed to various sports teams (rugby, football, softball, basketball, volleyball, table tennis, and track and field) in order to obtain their permission for cooperation in advance. The Ethics Committee of the Tokyo Medical University reviewed and approved this study (No. 3148). Informed consent was obtained from all participants prior to their responding to the questionnaire. The questionnaire included items regarding demographic information, daily and college life, sleep habits, sleep-related problems, and HRQOL.

The questionnaires were distributed to 375 collegiate athletes, of whom $308(82.3 \%)$ responded. Similarly, among the 311 non-athlete students who received questionnaires, 289 (92.9\%) responded (Fig 1). Of those who responded, participants were excluded from further analysis if: 1 ) they did not fully complete the questionnaire or provided invalid answers (non-athlete students, $n=42$; collegiate athletes, $n=13$ ), 2) 
they had neuropsychiatric or sleep disorders (non-athlete students, $n=6$; collegiate athletes, none), 3) they had been absent from team practice because of injury (non-athlete students, not applicable; collegiate athletes, $n=14$ ) , 4) they were female (non-athlete students, $n=67$; collegiate athletes, $n=63$ ), and 5) they had daytime naps (non-athlete students, $n=16$; collegiate athletes, $n=78$ ). Daytime naps were defined as having more than an hour of daytime sleep, three or more times per week. Consequently, the final sample comprised 158 non-athlete students and 140 collegiate athletes.

\section{Fig 1. Subject flow diagram.}

\section{Questionnaire items}

The questionnaire included the following demographic information: age, sex, body mass index (BMI), family living configuration (Please indicate the living configuration of your family. - living with your family members, living in a dormitory, or living alone), commuting time (How long does it take to get from your home to the university? - minutes), number of classes attended per week (How many classes do you have per week? - numbers), meal intake (Do you have a breakfast/lunch/dinner every day? - Yes or No), smoking habits (Do you currently smoke? - Yes or No), drinking habits (Do you currently drink alcohol? - Yes or No), and part-time jobs (Do you have a part-time job(s)? - Yes or No).

Regarding participants' sleep habits, habitual bedtime (What time do you usually go to bed on weekdays/weekend? - hours: minutes), wake-up time (What time do you usually get up on weekdays/weekend? - hours: minutes), and sleep onset latency (How long does it usually take you to fall asleep? - minutes) were assessed. The presence or absence of daytime sleepiness was assessed using the Epworth sleepiness scale (ESS), a widely used and validated tool for evaluating daytime sleepiness [14]. An ESS score of 11 or more indicated daytime sleepiness.

HRQOL was assessed using the short-form health survey (SF-8). The SF-8 is a simpler version of the SF36 , which is useful for evaluating the quality of life $[15,16]$. The SF-8 consists of the following domains: general health, physical functioning, role limitations due to physical health problems, bodily pain, vitality (energy/fatigue), social functioning, mental health, and role limitations due to emotional problems. Based on the scores of these items, mental component summary (MCS) and physical component summary (PCS) scores were calculated, and the general population standards for these scores were set at 50 . Worse PCS and MCS scores were defined as scores below the Japanese general population standard scores (49.84 for PCS and 50.09 for MCS), according to the user's manual [17]. Additionally, better HRQOL was defined when the participants had better scores for both PCS and MCS than the general Japanese population standard scores.

Statistical analysis

We first compared demographics using unpaired t-tests for continuous variables between non-athlete students and collegiate athletes. Similarly, chi-squared tests were used to compare categorical variables 
between the two groups. Effect sizes were estimated with $d$ for the unpaired t-tests and $\varphi$ for the chisquared tests.

To confirm the association between nocturnal sleep duration and better HRQOL, logistic regression analyses were conducted separately for the two groups, using the following independent variables: demographic variables (age, BMI, living alone or not, commuting time, number of classes per week, having three meals a day or not, and smoking and drinking habits), sleep-related variables (nocturnal sleep duration on weekdays, midpoint of sleep on weekdays), presence or absence of daytime sleepiness, and total duration of sports practice (only for collegiate athletes). All variables were initially examined in univariate models, and multivariate logistic regression analysis was subsequently carried out using the variables that showed significant associations in univariate models, in order to determine the main correlates controlling for confounding factors. Wald statistics were used to test the significance of the odds ratios (OR) yielded by the regression analysis. Receiver operating characteristic (ROC) curve analyses were performed to detect the cut-off point for nocturnal sleep duration that was sufficient to maintain a good HRQOL. All statistical analyses were conducted using IBM SPSS Statistics version 24 (SPSS Inc., Chicago, IL, USA). Statistical significance was set at $p<0.05$.

\section{Results}

Table 1 shows the demographic and descriptive variables for all participants. Collegiate athletes had a higher $\mathrm{BMI}(t=9.77, d f=226.26, p<0.001)$ and lower rates of living alone $\left(\chi^{2}(1)=13.28, \varphi=0.21, p<\right.$ $0.001)$, having part-time jobs $\left(\chi^{2}{ }_{(1)}=101.02, \varphi=0.58, p<0.001\right)$, and currently drinking alcohol $\left(\chi^{2}(1)\right.$ $=17.06, \varphi=0.24, p<0.001)$ and smoking $\left(\chi^{2}(1)=12.04, \varphi=0.20, p=0.001\right)$. However, they had a higher rate of having three meals a day $\left(\chi^{2}(1)=20.14, \varphi=0.26, p<0.001\right)$ compared with the non-athlete students. With respect to sleep schedules on weekdays, collegiate athletes had earlier bed times $(t=-$ 5.83, $d f=292.20, p<0.001)$, wake times $(t=-2.72, d f=284.14, p=0.007)$, and midpoints of sleep $(t=-$ $5.24, d f=289.62, p<0.001)$ compared with the non-athlete students. Similarly, for sleep schedules on weekends, bed times ( $t=-4.66, d f=296, p<0.001)$, wake times $(t=-3.39, d f=296, p=0.001)$, and midpoints of sleep $(t=-4.44, d f=294.04, p<0.001)$ were earlier for collegiate athletes than those for non-athlete students. Moreover, collegiate athletes had higher rates of worse PCS compared with the nonathlete students $\left(\chi^{2}(1)=17.20, \varphi=-2.40, p<0.001\right)$.

Univariate logistic regression analyses showed that only nocturnal sleep duration on weekdays was significantly associated with HRQOL in non-athlete students $(\mathrm{OR}=0.76,95 \%$ confidence interval $[\mathrm{Cl}]=$ $0.59 \llbracket 0.98, p=0.032$ ), whereas in collegiate athletes, having three meals a day, nocturnal sleep duration on weekdays, and midpoint of sleep were significantly associated with HRQOL $(\mathrm{OR}=0.293,95 \% \mathrm{Cl}=$ $0.099 \varangle 0.868, p=0.027 ; \mathrm{OR}=0.549,95 \% \mathrm{Cl}=0.334 \varangle 0.900, p=0.017 ; \mathrm{OR}=0.528,95 \% \mathrm{Cl}=0.283 \varangle 0.987, \mathrm{p}$ $=0.046$, respectively). Using the above variables in multivariate logistic regression analysis, nocturnal sleep duration on weekdays was significantly associated with HRQOL $(\mathrm{OR}=0.549,95 \% \mathrm{Cl}=0.334 \llbracket 0.900$, $p=0.017$ ) (Table 2 and 3 ). 
From the ROC curve analysis, the cut-off point for nocturnal sleep duration required to maintain good health in non-athlete students was 6.58 hours (area under the curve [AUC]: $0.62, p=0.049$, sensitivity: $65.8 \%$, specificity: $49.2 \%$ ). However, in collegiate athletes, the cut-off was 7.98 hours (AUC: $0.69, P=$ 0.013, sensitivity: $85.5 \%$, specificity: $56.2 \%$ ) (Fig 2).

\section{Figure 2. Cut-off points for optimal nocturnal sleep duration to maintain health-related quality of life}

The right shows the results for non-athlete students and the left shows the results for collegiate athletes

\section{Discussion}

The present study, which investigated sleep and lifestyle habits in collegiate athletes, is the first to report the optimal nocturnal sleep duration required for maintaining both physical and mental health in these individuals. Consequently, we demonstrated that bedtime, wake time, and the midpoint of sleep, both on weekdays and weekends, were earlier in collegiate athletes than in non-athlete students. However, there were no significant differences in nocturnal sleep duration between the groups, either on weekdays or weekends. These results indicate that collegiate athletes are more likely to have morningness sleep-wake schedules, compared with non-athlete students. Generally, younger individuals, such as collegiate students, have delayed sleep-wake schedules because of late bedtime resulting from their lifestyle (e.g., living alone, watching TV, or using the internet at midnight) [18]. However, in the present study, there were only a few collegiate athletes who stayed up late at night because they prioritized training or practice in their lifestyle. Indeed, there were fewer collegiate athletes who had part-time jobs compared with the nonathlete students. Nevertheless, a higher proportion of collegiate athletes had worse PCS than non-athlete students, despite having equivalent amounts of nocturnal sleep duration. These results reflected that a nocturnal sleep duration of even more than 7 hours was not sufficient for the optimal recovery of collegiate athletes from fatigue or injury from exercise.

Early morning training may be one of the reasons for collegiate athletes not getting enough sleep. It has been reported that the early-morning training sessions severely restrict the amount of sleep obtained by elite athletes [19]. In addition, considering that the age of the collegiate students is most associated with eveningness propensity [20], morningness sleep-wake schedule, which most of the collegiate athletes showed in the present study, may not be in synchronization with their endogenous biological rhythms. These observations suggest that collegiate athletes might not fall asleep even when they would go to bed early, resulting in insufficient sleep.

The findings of the present study emphasized that collegiate athletes needed 7.98 hours of nocturnal sleep to maintain both physical and mental HRQOL, which was 1.4 hours longer than that required by non-athlete students (6.58 hours). These results suggested that since collegiate athletes undergo more vigorous exercise training per day than non-athlete students, longer sleep times are required for recovery from physical exhaustion. However, the average sleep duration for collegiate athletes in the present study was 1 hour less than the optimal sleep duration for them and $81.2 \%$ of the collegiate athletes could not have nocturnal sleep duration at their optimal level. These results indicate that most collegiate athletes 
may be facing severe sleep loss. Although the subjects who had habitual daytime naps were excluded from the analyses because we focused on nocturnal sleep, the finding that a larger number of collegiate athletes had a habitual daytime nap than the non-athlete students may support this perspective. For collegiate athletes, the optimal nocturnal sleep duration has not been determined so far. To maintain collegiate athletes' mental/physical health and promote their future careers, knowledge about proper sleep hygiene is needed. The present results can guide not only collegiate athletes' lifestyles but also trainers' educational policies.

The present study has several limitations. First, the study did not investigate athletes across a wide range of sports. Reportedly, there are differences in sleep duration between individual and team sport athletes $[12,21]$. In the present study, although both individual and team sport athletes were included, more sports clubs should be recruited in future studies. Second, female athletes were excluded from the analysis in the present study. In females, it is known that the menstrual cycle affects sleep and mood [22-25]. Moreover, there are sex differences in the prevalence of insomnia [26], delayed sleep phase syndrome [27], short sleep [28,29], and other sleep-related problems [30]. Considering there are also sex differences in the rate of having a secondary disorder, such as depression, caused by sleep-related problems [31], optimal sleep duration is assumed to differ between males and females. This is why females were excluded from the current analysis. Future studies should determine the optimal sleep duration for females as well. Finally, factors affecting optimal sleep duration in collegiate athletes were not clarified. The increase in training intensity and mental pressure during the pre-game period reportedly decreases athletes' sleep duration [32]. Therefore, future studies should examine the relationship between training intensity, timing and length of training or periodization, and optimal sleep duration.

\section{Conclusions}

The present study revealed the sleep habits in collegiate athletes and the optimal sleep duration required for their physical and mental health. Although the nocturnal sleep duration was similar in collegiate athletes and non-athlete students, it was not enough for collegiate athletes to recover from physical exhaustion. Consequently, they had worse PCS scores. Collegiate athletes needed 7.98 hours of nocturnal sleep, which was longer than that for non-athlete students ( 6.58 hours). Around $80 \%$ of collegiate athletes in the present study had chronic insufficient sleep. Improving sleep habits and promoting sleep education are important for these individuals.

\section{Declarations}

\section{Ethics approval and consent to participate}

The study was reviwed and approved by the Ethics Committee of the Tokyo Medical University (No. 3148). Written informed consent was obtained from all participants prior to their responding to the questionnaire. 


\section{Consent for publication}

Not applicable.

\section{Availability of data and materials}

The data of this study is not publicly available, protected by the the Ethics Committee of the Tokyo Medical University for the current study.

\section{Competing interests}

The authors declare no competing interests.

\section{Funding}

This study was supported by a Ministry of Education, Culture, Sports, Science and Technology (MEXT) KAKENHI Grant-in-Aid for Young Scientists (B), No. 16K16608. No industrial support is declared.

\section{Authors' contributions}

YM designed the study, contributed to data collection and data analysis. TSS designed the study, contributed to data analysis and interpretation of results. All authors contributed to the manuscript writing, have read and approved the final version of the manuscript, and agreed with the order of presentation of the authors.

\section{Acknowledgements}

Not applicable.

\section{References}

1. Armstrong LE, VanHeest JL. The unknown mechanism of the overtraining syndrome: clues from depression and psychoneuroimmunology. Sports Med. 2002;32: 185-209. doi: 10.2165/00007256200232030-00003..

2. Davenne D. Sleep of athletes - problems and possible solutions. Biol Rhythm Res. 2009;40: 45-52. doi: 10.1080/09291010802067023.

3. Oliver SJ, Costa RJS, Laing SJ, Bilzon JLJ, Walsh NP. One night of sleep deprivation decreases treadmill endurance performance. Eur J Appl Physiol. 2009;107: 155-161. doi: 10.1007/s00421-009-11039.

4. Souissi N, Sesboüé B, Gauthier A, Larue J, Davenne D. Effects of one night's sleep deprivation on anaerobic performance the following day. Eur J Appl Physiol. 2003;89: 359-366. doi: 10.1007/s00421003-0793-7. 
5. Van Dongen HPA, Dinges DF. Sleep, circadian rhythms, and psychomotor vigilance.

Clin Sports Med. 2005;24: 237-249, vii, vii-viii. doi: 10.1016/j.csm.2004.12.007.

6. Chuah YML, Venkatraman V, Dinges DF, Chee MWL. The neural basis of interindividual variability in inhibitory efficiency after sleep deprivation. J Neurosci. 2006;26: 7156-7162.

doi: 10.1523/JNEUROSCI.0906-06.2006.

7. Blumert PA, Crum AJ, Ernsting M, Volek JS, Hollander DB, Haff EE, et al. The acute effects of twenty-four hours of sleep loss on the performance of national-caliber male collegiate weightlifters. $J$ Strength Cond Res. 2007;32: 185-209. doi: 10.1519/R-21606.1

8. Faubel R, Lopez-Garcia E, Gullar-Castillon P, Balboa-Castillo T, Gutierrez-Fisac JL, Banegas JR, et al. Sleep and health-related quality of life among older adults: A population-based cohort in Spain. Sleep. 2009;32: 1059-1068.

9. Lastella M, Lovell GP, Sargent C. Athletes' precompetitive sleep behaviour and its relationship with subsequent precompetitive mood and performance. Eur J Sport Sci. 2014;14(suppl 1): S123-S130. doi: 10.1080/17461391.2012.660505.

10. Leeder J, Glaister M, Pizzoferro K, Dawson J, Pedlar C. Sleep duration and quality in elite athletes measured using wristwatch actigraphy. J Sports Sci. 2012;30: 541-545.

doi: 10.1080/02640414.2012.660188.

11. Van Dongen HPA, Maislin G, Mullington JM, Dinges DF. The cumulative cost of additional wakefulness: Dose-response effects on neurobehavioral functions and sleep physiology from chronic sleep restriction and total sleep deprivation. Sleep. 2003;26: 117-126. doi: 10.1093/sleep/26.2.117.

12. Mah CD, Kezirian EJ, Marcello BM, Dement WC. Poor sleep quality and insufficient sleep of a collegiate student-athlete population. Sleep Heal. 2018;4: 251-257. doi: 10.1016/j.sleh.2018.02.005.

13. Simon JE, Docherty CL. Current health-related quality of life is lower in former division i collegiate athletes than in non-collegiate athletes. Am J Sports Med. 2014;42: 423-429.

doi: 10.1177/0363546513510393.

14. Johns MW. A new method for measuring daytime sleepiness: the Epworth sleepiness scale. Sleep. 1991;14: 540-545. doi: 10.1093/sleep/14.6.540.

15. Lefante JJ, Harmon GN, Ashby KM, Barnard D, Webber LS. Use of the SF-8 to assess health-related quality of life for a chronically ill, low-income population participating in the Central Louisiana Medication Access Program (CMAP). Qual Life Res. 2005;14: 665-673. doi: 10.1007/s11136-004-0784-0.

16. Ware JE, Kosinski M. Interpreting SF-36 summary health measures: a response. Qual Life Res. 2001;10: 405-413; discussion 415-420. doi: 10.1023/a:1012588218728. 
17. Fukuhara S, Suzukamo Y. Manual of the SF-8 Japanese version (in Japanese). Kyoto: Institute for Health Outcomes and Process Evaluation Research; 2004.

18. Asaoka S, Komada Y, Fukuda K, Sugiura T, Inoue Y, Yamazaki K. Exploring the daily activities associated with delayed bedtime of Japanese university students. Tohoku J Exp Med. 2010;221: 245249. doi: 10.1620/tjem.221.245.

19. Sargent C, Halson S, Roach GD. Sleep or swim? Early-morning training severely restricts the amount of sleep obtained by elite swimmers. Eur J Sport Sci. 2014;14(suppl 1): S310-S315. doi: 10.1080/17461391.2012.696711.

20. Roenneberg T, Kuehnle T, Juda M, Kantermann T, Allebrandt K, Gordijn M, et al. Epidemiology of the human circadian clock. Sleep Med Rev. 2007;11: 429-438. doi: 10.1016/j.smrv.2007.07.005.

21. Mah CD, Mah KE, Kezirian EJ, Dement WC. The effects of sleep extension on the athletic performance of collegiate basketball players. Sleep. 2011;34: 943-950. doi: 10.5665/SLEEP.1132.

22. Lastella M, Roach GD, Halson SL, Sargent C. Sleep/wake behaviours of elite athletes from individual and team sports. Eur J Sport Sci. 2015;15: 94-100. doi: 10.1080/17461391.2014.932016.

23. Manber R, Armitage R. Sex, steroids, and sleep: A review. Sleep. 1999;22: 540-555.

24. Brown SG, Morrison LA, Calibuso MJ, Christiansen TM. The menstrual cycle and sexual behavior: Relationship to eating, exercise, sleep, and health patterns. Women Health. 2008;48: 429-444. doi: 10.1080/03630240802575179.

25. Moline ML, Broch L, Zak R, Gross V. Sleep in women across the life cycle from adulthood through menopause. Sleep Med Rev. 2003;7: 155-177. doi: 10.1053/smrv.2001.0228.

26. Zhang B, Wing YK. Sex differences in insomnia: a meta-analysis. Sleep. 2006;29: 85-93. doi: 10.1093/sleep/29.1.85.

27. Schrader H, Bovim G, Sand T. The prevalence of delayed and advanced sleep phase syndromes. J Sleep Res. 1993;2: 51-55. doi: 10.1111/j.1365-2869.1993.tb00061.x.

28. Lauderdale DS, Knutson KL, Yan LL, Rathouz PJ, Hulley SB, Sidney S, et al. Objectively measured sleep characteristics among early-middle-aged adults: The CARDIA study. Am J Epidemiol. 2006;164: 516. doi: 10.1093/aje/kwj199.

29. Kronholm E, Härmä M, Hublin C, Aro AR, Partonen T. Self-reported sleep duration in Finnish general population. J Sleep Res. 2006;15: 276-290. doi: 10.1111/j.1365-2869.2006.00543.x.

30. Doi Y, Minowa M. Gender differences in excessive daytime sleepiness among Japanese workers. Soc Sci Med. 2003;56: 883-894. doi: 10.1016/s0277-9536(02)00089-8. 
31. Morita Y, Sasai-Sakuma T, Asaoka S, Inoue Y. The impact of a delayed sleep-wake schedule on depression is greater in women - A web-based cross-sectional study in Japanese young adults. Chronobiol Int. 2015;32: 952-958. doi: 10.3109/07420528.2015.1055756.

32. Fietze I, Strauch J, Holzhausen M, Glos M, Theobald C, Lehnkering H, et al. Sleep quality in professional ballet dancers. Chronobiol Int. 2009;26: 1249-1262. doi: 10.3109/07420520903221319.

\section{Tables}

Table 1. Comparison of demographic and descriptive characteristics between non-athlete college students and collegiate athletes. 


\begin{tabular}{|c|c|c|c|c|}
\hline Characteristics & $\begin{array}{c}\text { Non-athlete college } \\
\text { students } \\
(\mathrm{n}=158)\end{array}$ & $\begin{array}{l}\text { Collegiate } \\
\text { athletes } \\
(\mathrm{n}=140)\end{array}$ & $\begin{array}{l}\text { Effect } \\
\text { size }^{\mathrm{a}}\end{array}$ & $\begin{array}{c}\mathrm{p} \\
\text { Value }\end{array}$ \\
\hline Age (years) & $20.1(1.6)$ & $20.3(5.1)$ & 0.05 & 0.584 \\
\hline BMI $\left(\mathrm{kg} / \mathrm{m}^{2}\right)$ & $21.1(2.3)$ & $24.7(3.8)$ & 1.17 & 0.000 \\
\hline Living alone & $65(41.1)$ & $30(21.4)$ & 0.21 & 0.000 \\
\hline $\begin{array}{l}\text { Commuting time to college } \\
(\mathrm{min})\end{array}$ & $53.0(35.7)$ & $49.3(27.5)$ & 0.12 & 0.316 \\
\hline Number of classes per week & $10.4(4.8)$ & $10.7(3.1)$ & 0.07 & 0.557 \\
\hline Having three meals per day & $85(53.8)$ & $110(78.6)$ & 0.26 & 0.000 \\
\hline Currently drinking alcohol & $57(36.1)$ & $21(15.0)$ & 0.24 & 0.000 \\
\hline Currently smoking & $13(8.2)$ & $0(100.0)$ & 0.20 & 0.001 \\
\hline Having part-time jobs & $113(71.5)$ & $19(13.6)$ & 0.58 & 0.000 \\
\hline Bed time on weekdays & Oh 54min (1h 4min) & $\begin{array}{l}\text { Oh } 16 \mathrm{~min} \\
\text { (51min) }\end{array}$ & 0.67 & 0.000 \\
\hline Wake time on weekdays & $8 \mathrm{~h} 03 \min$ (1h 31min) & $\begin{array}{c}7 \mathrm{~h} 38 \mathrm{~min} \\
5 \mathrm{~min})\end{array}$ & 0.31 & 0.007 \\
\hline Sleep duration on weekdays & $6 \mathrm{~h} \mathrm{46min} \mathrm{(1h} \mathrm{38min)}$ & $\begin{array}{l}7 \mathrm{~h} 04 \min \\
9 \min )\end{array}$ & 0.21 & 0.063 \\
\hline $\begin{array}{l}\text { Midpoint of sleep on } \\
\text { weekdays }\end{array}$ & 4h 40min (1h 3min) & $\begin{array}{l}\text { 4h } 07 \mathrm{~min} \\
\text { (48min) }\end{array}$ & 0.60 & 0.000 \\
\hline Bed time on weekends & 1h $12 \min$ (1h 23min) & $\begin{array}{l}\text { Oh } 24 \min (1 \mathrm{~h} \\
36 \min )\end{array}$ & 0.54 & 0.000 \\
\hline Wake time on weekends & $9 \mathrm{~h} \mathrm{48min} \mathrm{(1h} \mathrm{52min)}$ & $\begin{array}{c}9 \mathrm{~h} 06 \min (1 \mathrm{~h} \\
41 \mathrm{~min})\end{array}$ & 0.39 & 0.001 \\
\hline Sleep duration on weekends & 8h 08min (2h 3min) & $8 \mathrm{~h} 23 \min (1 \mathrm{~h}$ & 0.13 & 0.249 \\
\hline $\begin{array}{c}\text { Total duration of practice } \\
\text { per week }\end{array}$ & - & $19.0(5.9)$ & ( & प \\
\hline Worse PCS (score < 49.85) & $83(52.5)$ & $106(75.7)$ & -0.24 & 0.000 \\
\hline Worse MCS (score < 50.09) & $80(50.6)$ & $67(47.9)$ & 0.03 & 0.632 \\
\hline Worse health-related QOL & $131(82.9)$ & $124(88.6)$ & -0.08 & 0.165 \\
\hline $\begin{array}{l}\text { Daytime sleepiness (ESS } \\
\text { score } \geqq 11 \text { ) }\end{array}$ & $28(17.7)$ & $33(23.6)$ & -0.07 & 0.212 \\
\hline
\end{tabular}

Continuous variables are expressed as mean (standard deviation) and compared using unpaired t-test; categorical variables are expressed as the number of subjects (\%) and compared using the chi-squared test.

BMI, body mass index; PCS, physical component summary; MCS, mental component summary; QOL, quality of life; ESS, Epworth sleepiness scale. 


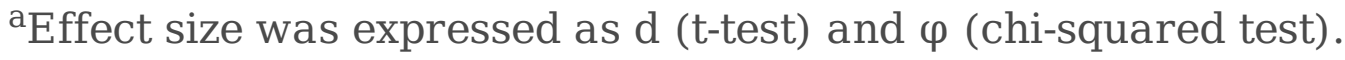

Table 2. Factors associated with Health-related Quality of Life for non-athlete students.

\begin{tabular}{lcc}
\hline & Univariate logistic regression analysis \\
\cline { 2 - 3 } & Odds ratio (95\% CI) & P-value \\
\hline Age & $\square$ & 0.731 \\
\hline BMI & $\square$ & 0.794 \\
\hline living alone & $\square$ & 0.580 \\
\hline Commuting time to college & $\square$ & 0.091 \\
\hline Having three meals a day & $\square$ & 0.979 \\
\hline The Number of class per a week & $\square$ & 0.712 \\
\hline Currently drinks alcohol & $\square$ & 0.965 \\
\hline Currently smokes & $\square$ & 0.198 \\
\hline Having part-time jobs & $\square$ & 0.067 \\
\hline Sleep duration on weekdays & $0.761(0.593 \square 0.977)$ & 0.032 \\
\hline Midpoint of nocturnal sleep on weekdays & $\square$ & 0.308 \\
\hline
\end{tabular}

BMI, body mass index; CI, confidence interval

Table 3. Factors associated with Health-related Quality of Life for athletes. 
Univariate logistic

regression analysis
Multivariate logistic

regression analysis

Odds ratio (95\% CI) P-value Odds ratio (95\% CI) P-value

Age

BMI

living alone

Commuting time to college

Having three meals a day

The Number of class per a

week

Currently drinks alcohol

Currently smokes

Having part-time jobs

Sleep duration on weekdays

Midpoint of nocturnal sleep on

$0.528(0.283 \square 0.987)$

$0.549(0.334 \square 0.900)$

0.074

0.797

प

प

0.520

0.017

$0.549(0.334 \square 0.900)$

0.017

weekdays

Total duration of practice per

प

0.696

a week

BMI, body mass index; CI, confidence interval

\section{Figures}


Non-athlete students

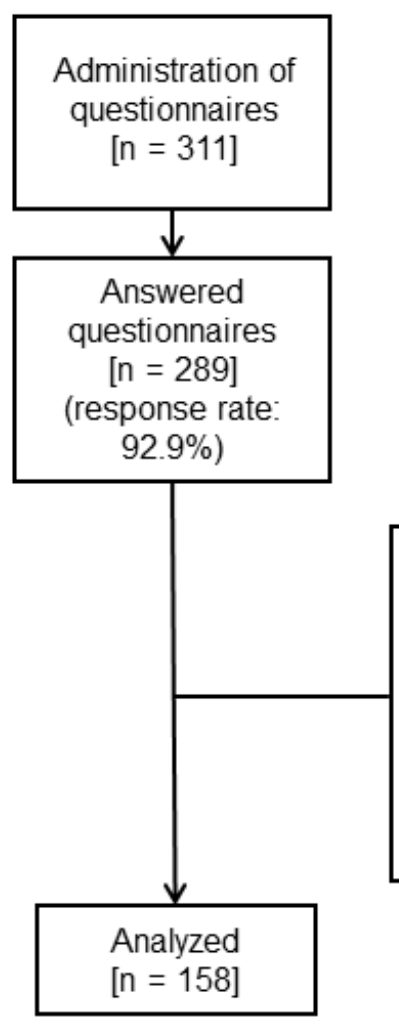

Collegiate athletes

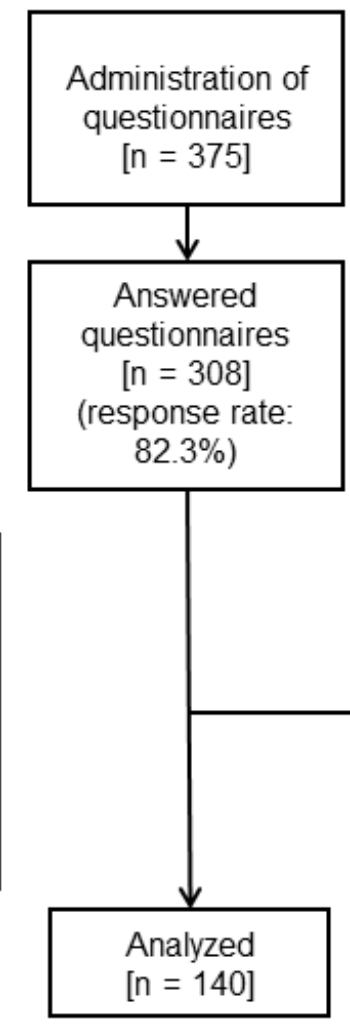

Excluded [ $n=168]$

1. People who provided invalid answers [ $=13$ ]

2. People who had been absent from practice in club team because of injury [ $n=14]$

3. Female $[n=63$ ]

4. Having daytime naps $[n=78]$

\section{Figure 1}

Subject flow diagram 
Non-athlete students

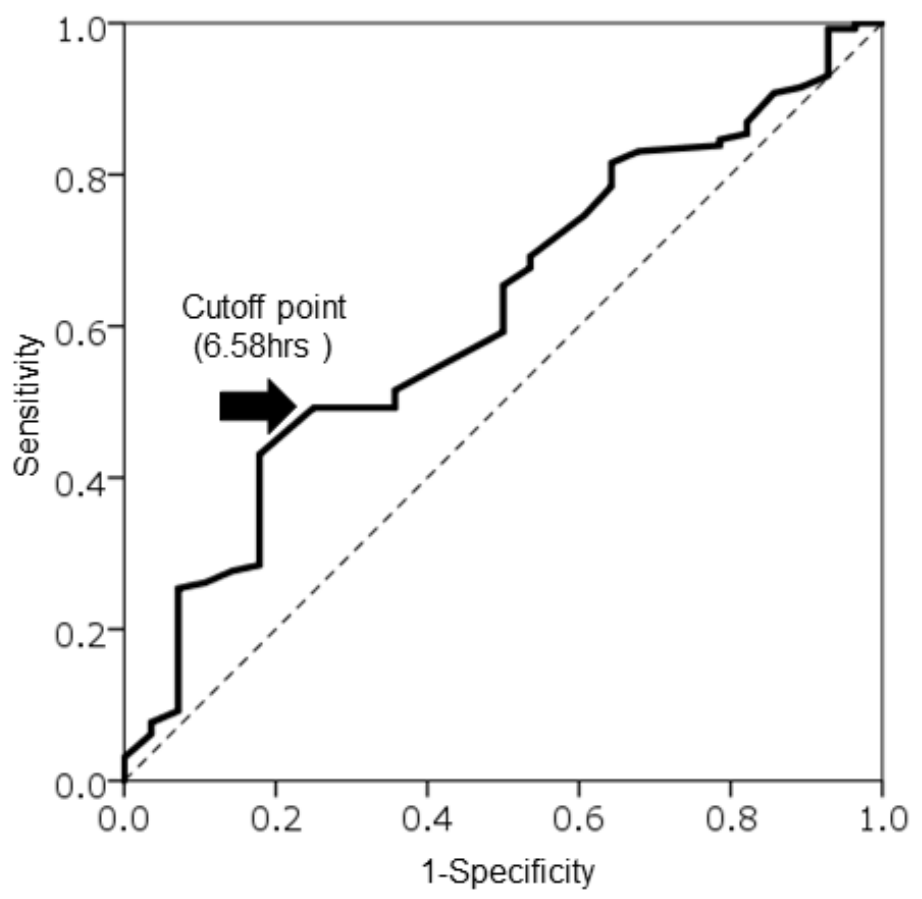

Collegiate athletes

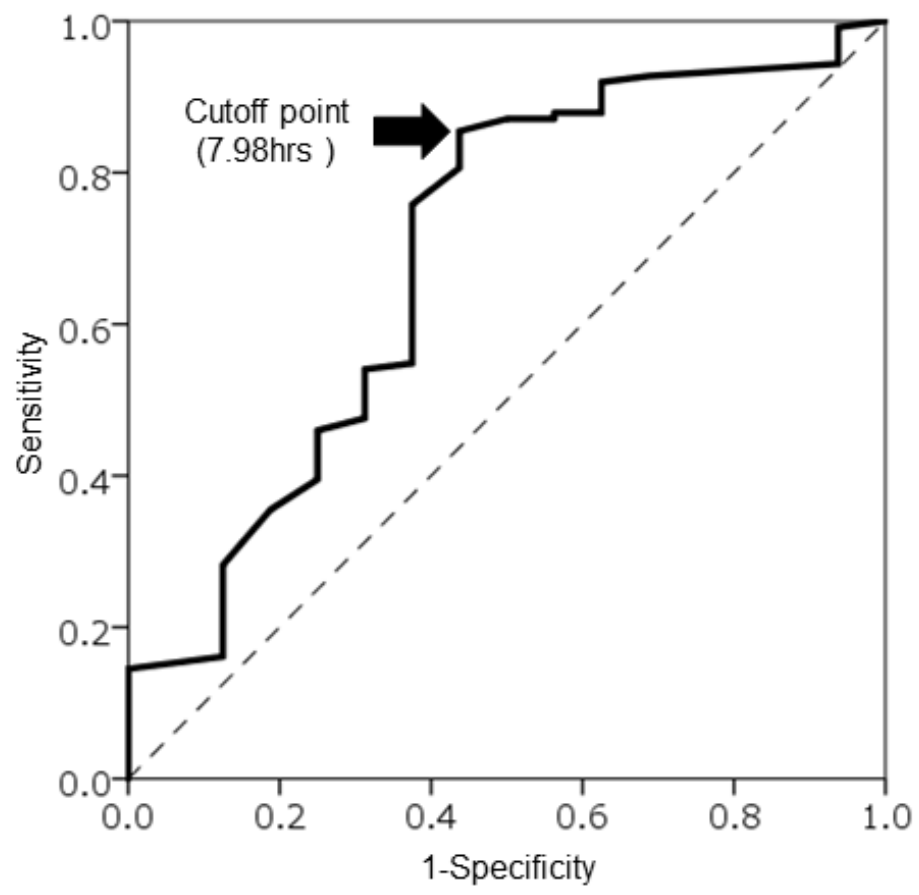

Figure 2

Cut-off points of optimal nocturnal sleep length to maintain health-related quality of life. The right shows the results for non-athlete students and the left shows the results for collegiate athletes. 